\title{
The "7+3" regimen in acute myeloid leukemia
}

\author{
Jacob M. Rowe
}

Shaare Zedek Medical Center, Jerusalem, Israel

E-mail: rowe@jimmy.harvard.edu

doi:10.3324/haematol.2021.280161

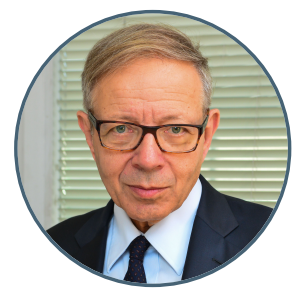

Cytosine arabinoside (NSC-63878) and daunorubicin (NSC-83142) therapy in acute nonlymphocytic leukemia

AUTHORs Yates JW, Wallace HJ Jr, Ellison RR, Holland JF

JOURNAL Cancer Chemother Rep. 1973;57(4):485-8. PMID: 4586956

$\mathrm{N}$ owadays, the majority of patients with acute myeloid leukemia (AML) achieve a complete remission and many are cured. This remarkable achievement takes place with a standardized induction regimen consisting of an anthracycline and cytarabine. The landmark paper in $1973-$ from the prestigious USA group of James Holland at the Roswell Park Memorial Institute in Buffalo, New York reported on an astounding complete remission rate of $63 \%$ among patients with both previously-treated and previouslyuntreated AML. The drugs used were the anthracycline, daunorubicin (formerly rubidomycin in France and daunomycin in the USA), and the pyrimidine antimetabolite, cytosine arabinoside. For a decade prior to this work, each of these drugs was shown to have potent anti-leukemic activity as single agents ${ }^{1,2}$ and even combinations of these two drugs had been reported. ${ }^{3}$ In all cases only a small number of remissions were achieved and they were of very short duration. The ultimate breakthrough came, not with the addition of new drugs, but after longer exposure of the leukemic cells to the combination of daunorubicin and cytarabine, as cytosine arabinoside is now known. This breakthrough combination and schedule of drugs for AML, widely known as the "7 and 3" regimen, dramatically changed the prognosis of patients, has remained the backbone of standard therapy for close to five decades, and, amazingly, is still going strong. This remarkable development has been at the core of the current constantly improving outlook for newly-diagnosed patients with AML. From having an incurable disease in the early 1970 s, approximately $35-40 \%$ of young adults can now expect to be long-term survivors - after starting with "7+3" induction therapy. Furthermore, and quite unthinkably even two decades ago, patients tolerate this combination well into their seventies.

\section{The $" 7+3 "$ Regimen}

\section{3}

\section{6 patients with $A M L$, age $17-78$ years}

$5 / 8$ previously untreaded

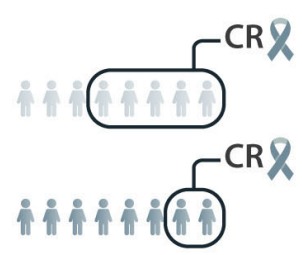

\begin{tabular}{|c|c|c|c|}
\hline Drug & Doses & Days & Delivery \\
\hline $\begin{array}{l}\text { Cytosine arabinosi } \\
\text { (NSC-638678) } \\
\text { Daunorubicin } \\
\text { (NSC-83142) }\end{array}$ & $100 \mathrm{mg} / \mathrm{m}^{2}$ & $\begin{array}{ccccccc}1 & 2 & 3 & 4 & 5 & 6 & 7 \\
0 & -0 & -0 & -0 & -0 & -0 & -0\end{array}$ & $\begin{array}{l}\text { Continuous } \\
\text { infusion }\end{array}$ \\
\hline
\end{tabular}

\section{References}

1. Ellison RR, Holland JF, Weil M, et al. Arabinosyl cytosine: a useful agent in the treatment of acute leukemia in adults. Blood. 1968;32(4):507-523.

2. Bernard J, Weil M, Boiron M, Jacquillat C, Flandrin G, Gemon MF. Acute promyelocytic leukemia: results of treatment by daunorubicin. Blood. 1973;41(4):489-496.

3. Crowther D, Powles RL, Bateman CJ, et al. Management of adult acute myelogenous leukaemia. Br Med J. 1973;1(5846):131-137. 